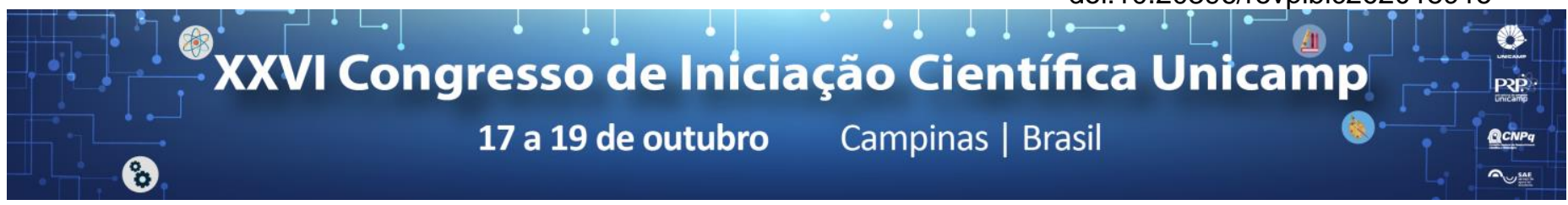

\title{
Panorama dos Planos Municipais de Saneamento Básico das bacias do PCJ - 10 anos após a Lei n.11.445/07.
}

\section{Luciane de O.L. Santos*, Mariana R.R. dos Santos.}

\begin{abstract}
Resumo
Tendo em vista que, ao falar de saneamento básico, deve-se pensar a oferta e amplo acesso a serviços de coleta e tratamento de esgoto, abastecimento de água, manejo de resíduos sólidos e drenagem urbana, reconhece-se que, no Brasil, esta ainda é uma demanda a ser trabalhada, uma vez que boa parte da população ainda vive sem acesso a estes serviços. Por sua vez, a Política Nacional de Saneamento Básico, Lei n.11.445/2007, declarou para todos os municípios, a necessidade de elaboração de planos de saneamento, os quais hoje são considerados obrigatórios para a obtenção de recursos federais a serem investidos em projetos de saneamento. Em 2017, completou-se dez anos da promulgação da referida lei e, neste contexto, o presente trabalho busca contribuir para a construção do panorama da atual situação dos municípios em relação à elaboração de seus planos municipais de saneamento, tomando por área de estudo as bacias dos rios Piracicaba, Capivari e Jundiaí (PCJ), abrangendo 70 municípios membros dos comitês PCJ. A pesquisa envolveu revisão bibliográfica e documental, além de consulta a bases de dados públicas e a órgãos públicos. Buscou-se ainda desenhar o perfil dos municípios com e sem planos e contribuir para o debate e encaminhamento de ações públicas nesta temática.
\end{abstract}

\section{Palavras-chave:}

Plano Municipal de Saneamento Básico, PCJ, Lei n.11.445/07.

\section{Introdução}

O Plano Municipal de Saneamento Básico (PMSB) deve contemplar as quatro componentes do setor de saneamento, que correspondem, conforme a Lei n.11.445/2007: ao abastecimento de água, esgotamento sanitário, limpeza urbana e manejo de resíduos sólidos, e manejo de águas pluviais (BRASIL, 2012).

Com prazo limite inicial previsto para 2010, a data para finalização dos planos municipais sofreu adiamentos: o primeiro para 2013, depois para 2015, o terceiro para dezembro de 2017 e, a mais recente prorrogação, em janeiro de 2018, para dezembro de 2019.

Considerando a importância do tema saneamento básico para o bem estar da população brasileira, o presente trabalho tem como objetivos organizar um panorama da situação dos Planos Municipais de Saneamento Básico das bacias do (PCJ) bem como identificar quais municípios da bacia possuem o plano e analisar se os panos possuem os temas indicados pela Política, inclusive a parte rural.

\section{Resultados e Discussão}

A pesquisa envolveu a realização de revisão bibliográfica, levantamento de dados com base em consultas a publicações oficiais e sítios eletrônicos de órgãos governamentais como, prefeituras municipais e órgãos ligados à gestão da água, além de bases de dados do IBGE e publicações e dados organizados pelo Trata Brasil (2017).

Após entrar em contato com as prefeituras dos municípios que compõem os comitês do PCJ, através de e-mail e/ou telefone, foi possível identificar a existência do PMSB em 52 cidades (que retornaram o contato ou possuem o PMSB disponível em site) e para os outros 18 municípios, não foi possível identificar o PMSB, ou por não estarem disponíveis nos sítios eletrônicos ou por não retornaram contato.

Como o prazo para entrega foi alterado quatro vezes pelo governo, é perceptível que os municípios protelam a elaboração do plano, porém sugere-se uma atenção para a urgência que o país tem para a área de saneamento. $\mathrm{Na}$ tabela 1 , são apresentados dados quanto à situação dos municípios das bacias PCJ em cada prazo.

Tabela 1. Situação dos municípios quanto à elaboração dos planos.

\begin{tabular}{|c|c|c|c|c|}
\hline Prazos & $\mathbf{2 0 1 0}$ & $\mathbf{2 0 1 3}$ & $\mathbf{2 0 1 5}$ & $\mathbf{2 0 1 7}$ \\
\hline $\begin{array}{c}\text { Municípios } \\
\text { que } \\
\text { possuem } \\
\text { PMSB }\end{array}$ & 1 & 15 & 23 & 11 \\
\hline
\end{tabular}

Fonte: Elaborado pelo autor (2018).

Todos os planos citam o meio rural de uma forma generalizada, diagnosticando e caracterizando a situação atual.

\section{Conclusões}

É possível concluir que os municípios membros do comitê do PCJ finalizaram seus respectivos planos e abordam os temas propostos pela Política, bem como, o meio rural, ainda que de forma generalizada. Vale ressaltar que os planos não acessados, não necessariamente não existem, mas não estavam disponíveis online ou não retornaram o contato.

\section{Agradecimentos}

Agradeço ao CNPQ pela concessão da bolsa para a pesquisa.

BRASIL. MINISTÉRIO DA SAÚDE. FUNDAÇÃO NACIONAL DE SAÚDE. Termo de referência para elaboração de planos municipais de saneamento básico. Procedimentos relativos ao convênio de cooperação técnica e financeira da Fundação Nacional de Saúde - Funasa/MS. Brasília, 2012.

TRATA BRASIL. $\quad(2017) . \quad$ Disponível
<http://www.tratabrasil.org.br/blog/2018/01/10/planos-saneamento-basico/>
Acesso em: 13 abr. 2017. $\mathrm{em}$ 